\title{
COMMENTARY
}

\section{High-frequency oscillatory ventilation with tracheal gas insufflation: the rescue strategy for brain-lung interaction}

\author{
Paolo Pelosi ${ }^{*}$ and Yuda Sutherasan ${ }^{2}$ \\ See related research by Vrettou et al., http://ccforum.com/content/17/4/R136
}

\begin{abstract}
The occurrence of moderate to severe acute respiratory distress syndrome due to traumatic brain injury is not uncommon and is associated with an extremely high incidence of morbidity and mortality. Owing to the complex interaction between the lung and brain, protective ventilation for the lung with lower tidal volume and higher positive end-expiratory pressure with or without mild hypercapnia might be harmful for the brain, and maintaining normocapnia or mild hypocapnia by increasing tidal volume or respiratory rate (or both) with lower positive endexpiratory pressure levels for protecting the brain might lead to ventilator-induced lung injury. Balancing the end-point between lungs and brain becomes a challenging issue, and non-conventional modes of mechanical ventilation might play a role in the more difficult clinical cases. In this commentary, the authors discuss the rationale, based on the physiologic principle of targeting both vital organs, of applying high-frequency oscillation and tracheal gas insufflation in acute respiratory distress syndrome patients with traumatic brain injury.
\end{abstract}

\section{Introduction}

In this issue of Critical Care, Vrettou and colleagues [1] introduce the alternative rescue strategies of highfrequency oscillation (HFO) and tracheal gas insufflation (TGI) in acute respiratory distress syndrome (ARDS) patients with traumatic brain injury (TBI). A quarter of patients with TBI develop subsequent pulmonary

\footnotetext{
* Correspondence: ppelosi@hotmail.com

${ }^{1}$ IRCCS AOU San Martino-IST, Department of Surgical Sciences and Integrated Diagnostics, University of Genoa, Largo Rosanna Benzi 8, 16132, Genova, Italy Full list of author information is available at the end of the article
}

dysfunction and are associated with high mortality. The main mechanisms of aggravating lung injury are stimulation of systemic inflammatory response and decreasing of lung tolerance to stress [2]. The evidence from animal models is that massive brain injury can increase the risk of ventilator-induced lung injury (VILI) [3-5].

The ventilator management in ARDS comprises low tidal volume $\left(\mathrm{V}_{\mathrm{T}}\right)$ of $6 \mathrm{~mL} / \mathrm{kg}$ ideal body weight, limited plateau pressure of the respiratory system at $30 \mathrm{~cm} \mathrm{H}_{2} \mathrm{O}$, and maintenance of the partial pressure of arterial oxygen $\left(\mathrm{PaO}_{2}\right)$ at between 55 and $80 \mathrm{~mm} \mathrm{Hg}$. This strategy may cause permissive hypercapnia to negatively affect intracranial pressure (ICP) by cerebral vasodilation in patients with severe TBI. Additionally, the increased ICP in combination with low $\mathrm{PaO}_{2}$ might promote cerebral tissue hypoxia. Therefore, a low $\mathrm{V}_{\mathrm{T}}$ strategy may result in a progressive deterioration of neurological outcome.

The main end-points of mechanical ventilator management in severe TBI are maintaining the partial pressure of carbon dioxide $\left(\mathrm{PaCO}_{2}\right)$ at between 31 and 35 $\mathrm{mm} \mathrm{Hg}$ and maintaining $\mathrm{PaO}_{2}$ at more than $60 \mathrm{~mm} \mathrm{Hg}$ or $100 \mathrm{~mm} \mathrm{Hg}[6,7]$. Trying to ventilate TBI patients with $\mathrm{V}_{\mathrm{T}}$ to keep that range of $\mathrm{PaCO}_{2}$ can aggravate VILI in patients either at risk of ARDS or with ARDS [8] (Figure 1). It was recently shown that higher $V_{T}$ ventilation can be associated with higher morbidity and mortality in patients with non-previously injured lungs [9]. Consequently, most of the clinical trials about protective ventilation in ARDS exclude patients with TBI.

HFO is an alternative approach in ventilating patients with severe ARDS. Several studies have reported a clear benefit in terms of improvement of oxygenation, prevention of further lung injury from low $\mathrm{V}_{\mathrm{T}}$ ventilation, and ability to recruit the lungs compared with conventional ventilation. However, two recent large randomized control trials have shown clear evidence that applying HFO 


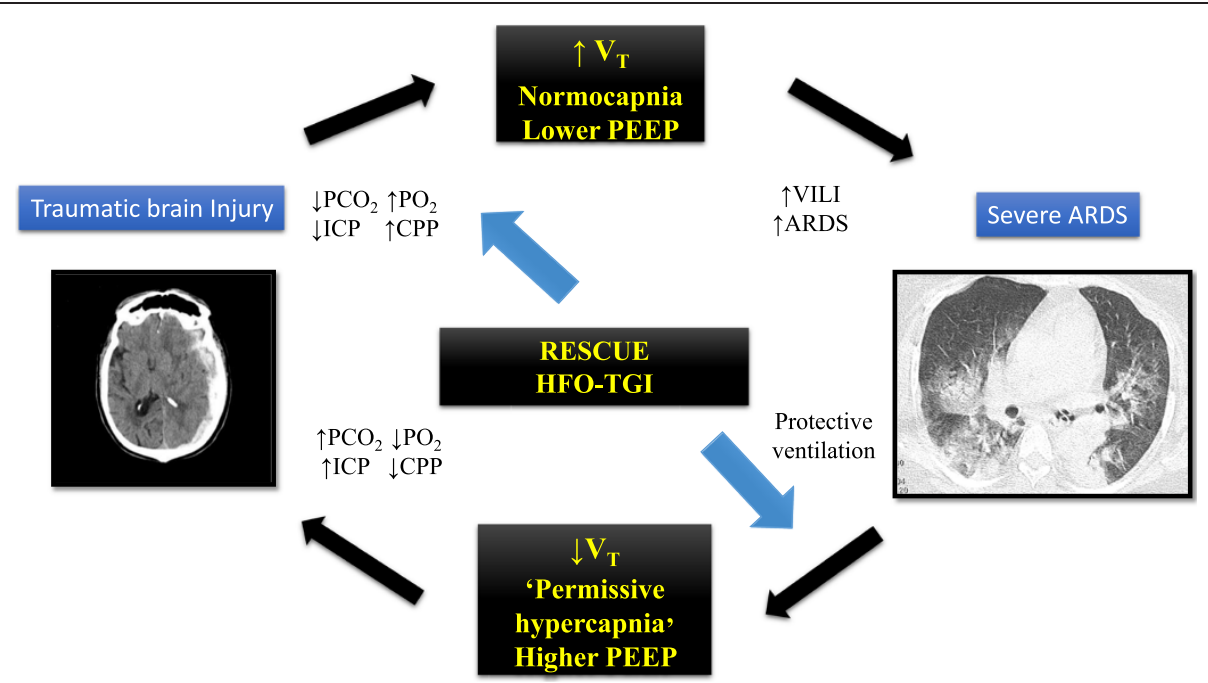

Figure 1 The effect of mechanical ventilation setting and acid-base disturbance on the brain and lung in acute respiratory distress syndrome (ARDS) and traumatic brain injury. CPP, cerebral perfusion pressure; HFO-TGl, combination of high-frequency oscillation with tracheal gas insufflation; ICP, intracranial pressure; $\mathrm{PCO}_{2}$, partial pressure of carbon dioxide; PEEP, positive end-expiratory pressure; $\mathrm{PO}_{2}$, partial pressure of arterial oxygen; VILI, ventilator-induced lung injury; $V_{T}$, tidal volume.

in moderate to severe ARDS is not superior to low $\mathrm{V}_{\mathrm{T}}$ ventilation [10] and might even be harmful in terms of in-hospital mortality [11]. Nevertheless, the first trial did not specify whether the TBI subgroup was included or excluded, and the second one clearly excluded the TBI subgroup. So we still have a question: are there any places for HFO? Vrettou and colleagues [1] make an effort to answer this question in this issue of Critical Care. The authors demonstrate the beneficial effect of the combination of HFO with TGI (HFO-TGI) on oxygenation, hemodynamics, cerebral perfusion pressure (CPP), and ICP in severe ARDS patients with TBI. The authors aimed to achieve optimal oxygenation and lower-to-normal $\mathrm{PaCO}_{2}$, avoiding possible adverse effects such as the increase of ICP and decrease of CPP.

\section{Commentary}

From previous study, HFO has been shown to improve oxygenation but also has been reported to increase $\mathrm{CO}_{2}$ retention. Another limitation is that the increase of intrathoracic pressure in HFO might lead to a decrease of cardiac output and consequently a worsening of CPP. Mentzelopoulos and colleagues [12] have shown that, in patients with early severe ARDS, HFO-TGI (compared with HFO) can improve oxygenation and conventional mechanical ventilation without having adverse effects on $\mathrm{PaCO}_{2}$ and hemodynamics. TGI can enhance $\mathrm{CO}_{2}$ elimination by (a) improving the $\mathrm{CO}_{2}$ washout from the proximal part of the anatomic dead space, (b) increasing lung volume and recruiting non-aerated lung regions by generating additional expiratory flow resistance, and (c) increasing the lung compliance, thus promoting a less injurious ventilation and better $\mathrm{CO}_{2}$ removal [13]. In another study, the authors demonstrated that additional recruitment maneuver can improve oxygenation and lung compliance without disturbing hemodynamics in ARDS without TBI [14]. HFO-TGI, compared with conventional ventilation, improves lung compliance and $\mathrm{PaO}_{2} /$ fraction of inspired oxygen ratio while decreasing the plateau pressure of the respiratory system and the incidences of higher ICP and lower CPP. Furthermore, the improvements in ICP and CPP were demonstrated 4 hours after applying HGO-TGI. The main mechanisms of improvement of cerebral hemodynamics during HFOTGI are (a) the lowering of mean tracheal pressure to below the actual mean airway pressure displayed by ventilator and (b) lung recruitment without over-distension by the previously mentioned mechanisms.

However, the application of TGI can lead to bronchial mucosal damage from the jet stream and retention of secretion. These complications are not reported in this study. However, the authors applied HFO-TGI for less than 12 hours. The recruitment maneuver during preHFO-TGI might lead to transient hypotension and is not life-threatening. An alternative could be the use of extracorporeal $\mathrm{CO}_{2}$ removal, but this technique might pose a risk in patients with TBI [15].

\section{Conclusions}

HFO-TGI may be considered an alternative rescue ventilation strategy in patients with TBI and severe ARDS. This method might provide non-injurious ventilation for the lung and optimal gas-exchange to protect the brain. When these techniques are used, an intensive 
monitoring of the respiratory function as well as brain physiology is mandatory.

\section{Abbreviations}

ARDS: acute respiratory distress syndrome; $\mathrm{CO}_{2}$ : carbon dioxide; CPP: cerebral perfusion pressure; HFO: high-frequency oscillation; HFO-TGI: combination of high-frequency oscillation with tracheal gas insufflation; ICP: intracranial pressure; $\mathrm{PaCO}_{2}$ : partial pressure of carbon dioxide; $\mathrm{PaO}_{2}$ : partial pressure of arterial oxygen; TBI: traumatic brain injury; TGI: tracheal gas insufflation; VILI: ventilator-induced lung injury; $V_{T}$ : tidal volume.

\section{Competing interests}

The authors declare that they have no competing interests.

\section{Authors' contributions}

Both authors contributed to manuscript preparation and read and approved the final manuscript.

\section{Author details}

${ }^{1}$ IRCCS AOU San Martino-IST, Department of Surgical Sciences and Integrated Diagnostics, University of Genoa, Largo Rosanna Benzi 8, 16132, Genova, Italy. ${ }^{2}$ Ramathibodi Hospital, Rama 6 Road, Mahidol University, 10400, Bangkok, Thailand.

Published: 27 August 2013

\section{References}

1. Vrettou CS, Zakynthinos SG, Malachias S, Mentzelopoulos SD: High frequency oscillation and tracheal gas insufflation in patients with severe acute respiratory distress syndrome and traumatic brain injury: an interventional physiological study. Crit Care 2013, 17:R136.

2. Pelosi P, Severgnini P, Chiaranda M: An integrated approach to prevent and treat respiratory failure in brain-injured patients. Curr Opin Crit Care 2005, 11:37-42.

3. Pelosi P, Rocco PR: The lung and the brain: a dangerous cross-talk. Crit Care 2011, 15:168.

4. Heuer JF, Pelosi P, Hermann P, Perske C, Crozier TA, Bruck W, Quintel M: Acute effects of intracranial hypertension and ARDS on pulmonary and neuronal damage: a randomized experimental study in pigs. Intensive Care Med 2011, 37:1182-1191.

5. Quilez ME, Fuster G, Villar J, Flores C, Marti-Sistac O, Blanch L, Lopez-Aguilar $\mathrm{J}$ : Injurious mechanical ventilation affects neuronal activation in ventilated rats. Crit Care 2011, 15:R124.

6. Brain Trauma Foundation, American Association of Neurological Surgeons, Congress of Neurological Surgeons: Guidelines for the management of severe traumatic brain injury. J Neurotrauma 2007, 24:S1-S106.

7. Helmy A, Vizcaychipi M, Gupta AK: Traumatic brain injury: intensive care management. Br J Anaesthesia 2007, 99:32-42.

8. Mascia L, Zavala E, Bosma K, Pasero D, Decaroli D, Andrews P, Isnardi D, Davi A, Arguis MJ, Berardino M, Ducati A, Brain IT group: High tidal volume is associated with the development of acute lung injury after severe brain injury: an international observational study. Crit Care Med 2007, 35:1815-1820

9. Serpa Neto A, Cardoso SO, Manetta JA, Pereira VG, Esposito DC, Pasqualucci Mde O, Damasceno MC, Schultz MJ: Association between use of lungprotective ventilation with lower tidal volumes and clinical outcomes among patients without acute respiratory distress syndrome: a meta-analysis. JAMA 2012, 308:1651-1659.

10. Young D, Lamb SE, Shah S, MacKenzie I, Tunnicliffe W, Lall R, Rowan K, Cuthbertson BH, Group OS: High-frequency oscillation for acute respiratory distress syndrome. N Engl J Med 2013, 368:806-813.

11. Ferguson ND, Cook DJ, Guyatt GH, Mehta S, Hand L, Austin P, Zhou Q, Matte A, Walter SD, Lamontagne F, Granton JT, Arabi YM, Arroliga AC, Stewart TE, Slutsky AS, Meade MO, OSCILLATE Trial Investigators; Canadian Critical Care Trials Group: High-frequency oscillation in early acute respiratory distress syndrome. N Engl J Med 2013, 368:795-805.

12. Mentzelopoulos SD, Roussos C, Koutsoukou A, Sourlas S, Malachias S, Lachana A, Zakynthinos SG: Acute effects of combined high-frequency oscillation and tracheal gas insufflation in severe acute respiratory distress syndrome. Crit Care Med 2007, 35:1500-1508.
13. Mentzelopoulos SD, Theodoridou M, Malachias S, Sourlas S, Exarchos DN, Chondros D, Roussos C, Zakynthinos SG: Scanographic comparison of high frequency oscillation with versus without tracheal gas insufflation in acute respiratory distress syndrome. Intensive Care Med 2011, 37:990-999.

14. Mentzelopoulos SD, Malachias S, Zintzaras E, Kokkoris S, Zakynthinos E, Makris D, Magira E, Markaki V, Roussos C, Zakynthinos SG: Intermittent recruitment with high-frequency oscillation/tracheal gas insufflation in acute respiratory distress syndrome. Eur Respir J 2012, 39:635-647.

15. Bein T, Scherer MN, Philipp A, Weber F, Woertgen C: Pumpless extracorporeal lung assist ( $\mathrm{pECLA}$ ) in patients with acute respiratory distress syndrome and severe brain injury. J Trauma 2005, 58:1294-1297.

doi:10.1186/1364-8535-17-R179

Cite this article as: Pelosi and Sutherasan: High-frequency oscillatory ventilation with tracheal gas insufflation: the rescue strategy for brainlung interaction. Critical Care 2013 17:R179. 